\title{
A Methodology for Modeling the Influence of Construction Machinery Operators on Productivity and Fuel Consumption
}

\author{
Reno Filla ${ }^{1,2}$ \\ ${ }^{1}$ Volvo Construction Equipment AB, Research \& Development, \\ SE - 63185 Eskilstuna, Sweden \\ ${ }^{2}$ Linköping University, Department of Management and Engineering, \\ SE - 58183 Linköping, Sweden
}

\begin{abstract}
This paper is concerned with modeling the actions of a human operator of construction machinery and integrating this operator model into a large, complex simulation model of the complete machine and its environment. Because human operators to a large degree affect how the machine is run, adaptive operator models are a necessity when the simulation goal is quantification and optimization of productivity and energy efficiency. Interview studies and test series have been performed to determine how professionals operate wheel loaders. Two models using different approaches were realized and integrated into a multi-domain model for dynamic simulation. The results are satisfactory and the methodology is easily usable for other, similar situations.
\end{abstract}

Keywords: dynamic simulation, operator model, driver model.

\section{Introduction}

In this ongoing research on simulation in the conceptual design of complex working machines, a wheel loader was chosen as the object of study, although others can be found not only in the field of construction machinery, but also in other sectors such as agriculture, forestry, and mining. Common factors are that these machines consist of at least two working systems that are used simultaneously and that the human operator is essential to the performance of the total system.

In the case of a wheel loader, drive train and hydraulics are both equally powerful and compete for the limited engine torque. Figure 1 visualizes how the primary power from the diesel engine is split up between hydraulics and drive train (outer loop) in order to create lift/tilt movements of the bucket and traction of the wheels, but is connected again when filling the bucket in e.g. a gravel pile. In this situation, the traction force from the drive train, acting between wheels and ground, creates a reaction force between gravel pile and bucket edge, which in turn counteracts lift and tilt forces from hydraulics, and vice versa [1].

The inner loop in Fig. 1 shows how the human operator interacts with the wheel loader. In order to fill the bucket, the operator needs to control three motions simultaneously: a forward motion that also exerts a force (traction), an upward motion (lift) 


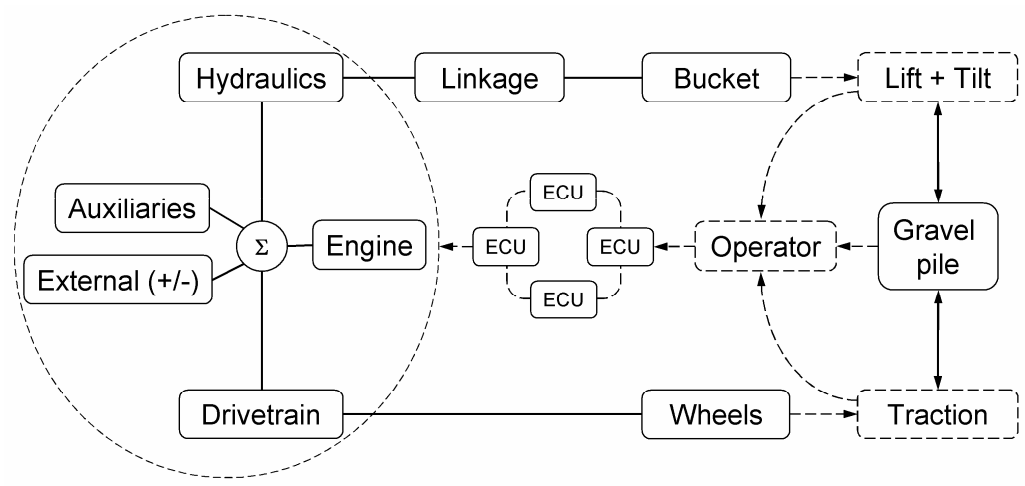

Fig. 1. Simplified power transfer and control scheme of a wheel loader during bucket loading

and a rotating motion of the bucket to fit in as much material as possible (tilt). This is similar to how a simple manual shovel is used. However, in contrast to a manual shovel, the operator of a wheel loader can only observe, and cannot directly control these three motions. Instead, he or she has to use different subsystems of the machine in order to accomplish the task. The gas pedal controls engine speed, while lift and tilt lever control valves in the hydraulics system that ultimately control movement of the linkage's lift and tilt cylinder, respectively.

The difficulty lies in that no operator control directly affects only one single motion. The gas pedal controls engine speed, which affects both the machine's longitudinal motion and via the hydraulic pumps the speeds of the lift and tilt cylinders. The linkage between the hydraulic cylinders and the bucket acts as a non-linear planar transmission and due to its design a lift movement will also change the buckets tilt angle and a tilt movement affects the bucket edge's height above the ground. In summary, there are many of interdependencies and it thus takes a certain amount of training to be able to use the machine efficiently.

In modern wheel loaders the operator does not control major components and subsystems directly, but via electronic control units (ECUs). This makes it possible to give the operator support, e.g. by controlling the cylinder speeds in such a manner that the non-linearity of the linkage is compensated for and thus the speed of bucket lift and tilt is proportional to the angle of the tilt and lift lever. Certain aspects of machine operation, for instance a typical brake-and-reverse driving sequence, can also be developed to be semi-automatic or fully automated.

If a simulation is required to capture the full scope of the interaction between the machine, its environment, and its operator, all three must be modeled at an appropriate level of detail in order to give valid results as regards such complex total system properties as productivity and fuel consumption / energy efficiency. This is an aspect that is traditionally neglected, because the modeling needs to be extended beyond the technical system. 


\section{Literature study}

\subsection{Working Cycle}

The knowledge regarding wheel loader operation and working cycles presented in this paper has been derived from the author's own wheel loader experience and to a large extent from discussions with colleagues, test engineers, product specialists, and professional operators at Volvo. Most of these discussions were not formally structured, but rather conducted in an ad-hoc manner. However, some unstructured research interviews were carried out and one interview, conducted with a professional test operator, was recorded in the form of a semi-structured research interview. Furthermore, many measurements were performed and the results and implications discussed. Most of these reports are internal, but some MSc theses [2, 4, 5] and academic papers [6] are available in the public domain.

In [7], Gellerstedt published wheel loader operator's thoughts and reasoning and also documented some typical working cycles with photos and test data.

Furthermore, non-academic publications like operating manuals and instruction material available from machine manufacturers contain useful information.

\subsection{Operator Models}

Surprisingly little could be found in a literature review restricted to working machines and designing operator models for the purpose of simulation. Zhang et al. validate control strategies by conducting human-operated experiments in their Earthmoving Vehicle Powertrain Simulator. The corresponding paper [3] gives some insight into their reasoning regarding human-machine interaction. They acknowledge the difference between task-oriented jobs (such as wheel loader operation in a short loading cycle) and reference-oriented jobs (e.g. driving a car).

Some more work can be found in the field of autonomous excavation. Hemami specifically examines bucket filling in [8] and also Wu [9], starting off with analyzing wheel loader operation in general, later focuses on the bucket filling phase. Both handle the problem as one that can be solved by following predefined trajectories.

An abundance of literature in the aerospace and in the automotive sector deals with pilot models and parameter identification for the purpose of predicting pilot behavior over the next seconds [10 - 14]. Among the techniques employed are path-following controllers, Kalman filters, fuzzy logic, and neural networks. Such models are used for advanced control problems like pilot or driver assistance systems and energy management of hybrids. But the inverse problem is also considered: assessing handling qualities in certain predefined maneuvers.

\section{Development Methodology}

\subsection{Required Model Features}

Since the application of the operator model is in simulation in conceptual design, i.e. before any physical prototype is available, it has been deemed important that the model not be hard-coded in any way. Using fixed time, speed or position references 
and predefined trajectories, there is a significant risk that these references are only valid for the machine that was used during development of the operator model, but result in large deviations for a new machine with as yet unknown properties. Therefore, any such references must be weak ones and either constant for all machines of any size and architecture, or possible to formulate parametrically, i.e. as a function of bucket length, loading capacity, wheel distance or similar.

Also, in order to mimic the human operator as close as possible, the operator model must also be strictly separated from both machine and environment model, and its inputs and outputs must be limited to those of a human operator.

\subsection{Orientating Interviews}

These interviews are unstructured and aim to establish basic knowledge of the type of cycle to model, its features, and its characteristics.

In our work, interviewing owners and operators of wheel loaders at different sites has lead to the conclusion that each working place is unique in its parameters, but the short loading cycle (Fig. 2) is highly representative of the majority of applications.

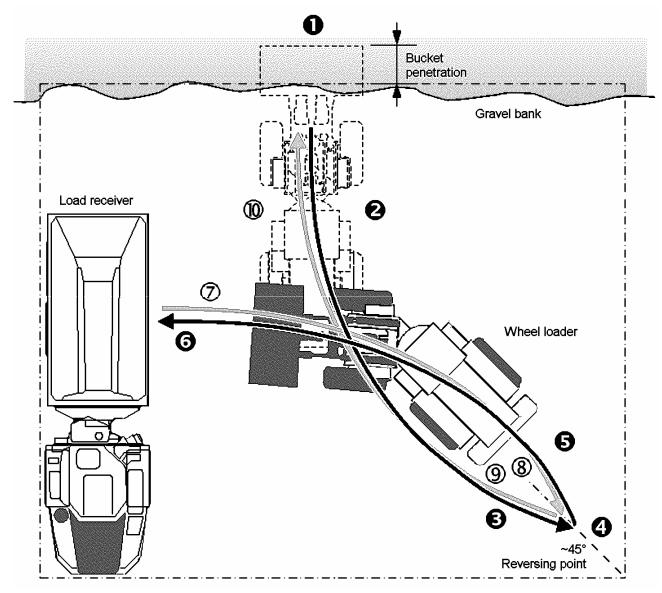

Fig. 2. Short loading cycle

Typical for this cycle is bucket loading of material on an adjacent load receiver within a time frame of 25-35 seconds. The aforementioned problems with interactions between subsystems are highly present.

Several phases can be identified (Fig. 2), which Table 1 describes briefly. A more detailed exploration of the short loading cycle can be found in [1].

Essentially all operators described their operation commands as triggered by events, both from the machine and its environment, sometimes guided by weak speed or position references. It has therefore been found meaningful to develop rule-based operator models and all subsequent steps are based on that decision. 
Table 1. Phases of the short loading cycle

\begin{tabular}{|c|c|c|}
\hline$\#$ & Phase & Description \\
\hline 1 & Bucket filling & $\begin{array}{l}\text { Bucket is filled by simultaneously controlling the machine } \\
\text { speed and lift and tilt functions. }\end{array}$ \\
\hline 2 & Leaving bank & $\begin{array}{l}\text { Operator drives backwards towards the reversing point and } \\
\text { steers the machine to achieve the characteristic V-pattern. }\end{array}$ \\
\hline 3 & Retardation & $\begin{array}{l}\text { Is started some time before phase } 4 \text { and can be either } \\
\text { prolonged or shortened by controlling the gas pedal and the } \\
\text { service brakes. }\end{array}$ \\
\hline 4 & Reversing & $\begin{array}{l}\text { Begins when the remaining distance to the load receiver will } \\
\text { be sufficient for the lift hydraulics to achieve the bucket } \\
\text { height necessary for emptying during the time it takes to get } \\
\text { there. }\end{array}$ \\
\hline 5 & $\begin{array}{l}\text { Towards } \\
\text { load receiver }\end{array}$ & $\begin{array}{l}\text { The operator steers towards the load receiver, thus completing } \\
\text { the } V \text {-pattern. The machine arrives perpendicular to the load } \\
\text { receiver. }\end{array}$ \\
\hline 6 & Bucket emptying & $\begin{array}{l}\text { The machine is driven forward slowly, the loading unit being } \\
\text { raised and the bucket tilted forward at the same time. }\end{array}$ \\
\hline 7 & $\begin{array}{l}\text { Leaving } \\
\text { load receiver }\end{array}$ & $\begin{array}{l}\text { Operator drives backwards towards the reversing point, while } \\
\text { the bucket is lowered to a position suitable for driving. }\end{array}$ \\
\hline 8 & $\begin{array}{l}\text { Retardation } \\
\text { and reversing }\end{array}$ & $\begin{array}{l}\text { Not necessarily executed at the same location as in phases } 3 \\
\text { and } 4 \text {, because lowering an empty bucket is faster than raising } \\
\text { a full one. }\end{array}$ \\
\hline 9 & Towards bank & $\begin{array}{l}\text { The machine is driven forward to the location where the next } \\
\text { bucket filling is to be performed, the bucket being lowered } \\
\text { and aligned with the ground at the same time. }\end{array}$ \\
\hline 10 & $\begin{array}{l}\text { Retardation } \\
\text { at bank }\end{array}$ & $\begin{array}{l}\text { Often combined with the next bucket filling by using the } \\
\text { machine's momentum to drive the bucket into the gravel pile. }\end{array}$ \\
\hline
\end{tabular}

\subsection{In-Depth Interviews}

In this next step, semi-structured research interviews are conducted with professional operators who are able to verbally express how they use the machine in the working task at hand. It is important to go through each cycle phase in detail, noting what event triggered a reaction, which controls are applied and how long, alternate scenarios, what defines success, what defines failure etc.

In our work we were able to interview one product specialist who was also a professional test operator and, more importantly, experienced machine instructor and thus used to teaching people how to operate wheel loaders in an efficient manner. Additionally, many brief unstructured interviews were performed with colleagues of a similar background. Table 2 lists one result: a guide to how to fill the bucket.

As another example, Table 3 shows how phases 2 to 4 are performed, i.e. leaving bank, retardation, and reversing. 
Table 2. Bucket filling

\begin{tabular}{ll}
\hline$\#$ & Description \\
\hline 1 & Accelerate to a certain velocity \\
2 & Shift to lowest gear (kick-down) when bucket edge meets gravel pile \\
3 & Apply gas pedal to increase traction and push bucket into the pile \\
4 & In case of slippage between tires and ground, lift bucket a little more to \\
& increase load on front axle (increases traction) \\
5 & If bucket gets stuck in pile, tilt bucket backwards a little \\
6 & If bucket gets stuck in pile, reduce traction a little \\
7 & Follow the slope of the pile in a carving manner \\
8 & Lift continuously, apply tilt function without releasing lift lever \\
9 & Leave pile with bucket below tipping height (straight lifting arms) \\
10 & Tilt bucket fully back \\
\hline
\end{tabular}

Table 3. Leaving bank, retardation, and reversing

\begin{tabular}{|c|c|}
\hline \# & Description \\
\hline 1 & Put transmission into reverse gear \\
\hline 2 & Start lifting \\
\hline 3 & $\begin{array}{l}\text { Apply gas pedal to accelerate, but keep machine speed below shifting } \\
\text { point for gear } 3\end{array}$ \\
\hline 4 & Steer machine into right curve (if load receiver is standing to the left) \\
\hline 5 & $\begin{array}{l}\text { Adjust steering so that machine can arrive perpendicular to the load } \\
\text { receiver }\end{array}$ \\
\hline 6 & $\begin{array}{l}\text { Choose reversing point so that distance to load receiver is enough for } \\
\text { bucket to reach sufficient height for emptying, if continuously lifted }\end{array}$ \\
\hline 7 & Retard economically by releasing gas pedal \\
\hline 8 & Steer back machine into straight position \\
\hline 9 & Apply brakes until machine almost stands still \\
\hline 10 & Put transmission into forward gear \\
\hline
\end{tabular}

\subsection{Recording and Analyzing Test Series}

Together with video recordings of the machine in operation and possibly also from inside the cab, measurement data can serve as an additional source of information.

In our work we equipped test machines with a data acquisitioning system and recorded control inputs and major machine variables, such as engine speed, traveling distance, bucket height and angle (etc). We also found video recordings of the machine in operation to be a valuable complement.

\subsection{Deriving General Rules and Constraints}

The results from interview studies and possibly additional measurements are now to be transformed into general, non-machine specific rules and constraints. This is the last step before coding the operator model, which makes it necessary to construct the rules and constraints in a way that is possible to implement.

In our work one result was a quantification of values for "a little" and "certain", the vague vocabulary used in Table 2 . For instance, the initial velocity in rule \#1 was set to $3 \mathrm{~km} / \mathrm{h}$ and the trigger for kick-down in rule \#2 was set to a bucket penetration 
depth of $200 \mathrm{~mm}$. The height in rule \#9 was set to $1 / 3$ of maximum lifting height. Also, the working place was set up parametrically, more details can be found in [16].

\subsection{Implementation}

The derived general rules and constraints are now to be implemented as execution paths of a finite state machine. In our work two operator models have been realized. In both cases the model of the technical system and the working place were developed and simulated in ADAMS, a three-dimensional multi-body system code. Both operator models are separate entities and the information exchange with machine and environment is limited to operator inputs and outputs similar to a human being, i.e. the operator has neither insight nor influence at a deeper level.The first operator model has focused on the bucket filling and has been realized as state equations in ADAMS with an algorithm reminiscent of fuzzy logic. This is explained in more detail in [15]. The second operator model, with a focus on the remaining phases of the short loading cycle, has been realized in Stateflow (Fig. 3) and co-simulated with ADAMS [16]. Table 4 shows how cycle phase 2 has been realized with two parallel paths.

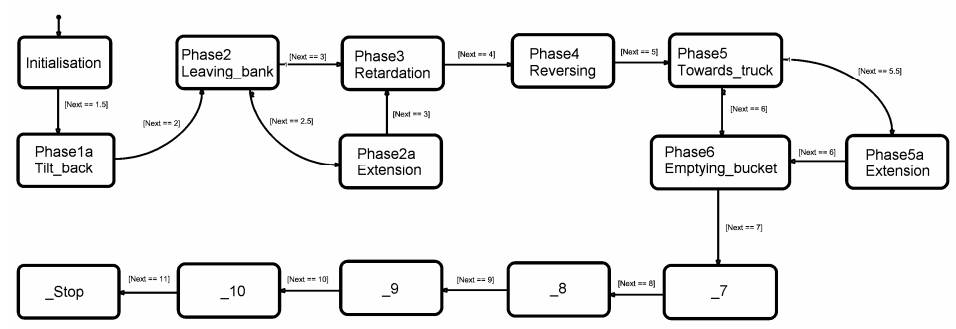

Fig. 3. Top level view of the operator model in Stateflow [16]

Table 4. Applied steps in phase 2 of the operator model

\begin{tabular}{ll}
\hline$\#$ & Description \\
\hline A1 & Apply full lift and full gas pedal. \\
A2 & $\begin{array}{l}\text { Steer machine so that reversing will take place with machine pointing at } \\
\text { workplace origin }\left(\text { angle at ca } 45^{\circ} \text { ). Calculate required steering angle. }\right.\end{array}$ \\
A3 & $\begin{array}{l}\text { Apply full steering, reduce and stop when required steering angle is } \\
\text { reached. }\end{array}$ \\
A4 & Begin steering back when machine is about to point at workplace origin. \\
A5 & Keep driving backwards until path B terminates this phase. \\
B1 & $\begin{array}{l}\text { Wait for machine to pass load receiver (fist geometric possibility to } \\
\text { reverse). }\end{array}$ \\
B2 & $\begin{array}{l}\text { Wait for extrapolated remaining lifting time to be lower than remaining } \\
\text { extrapolated driving time to load receiver. }\end{array}$ \\
B3 & $\begin{array}{l}\text { Calculate required steering angle for perpendicular arrival at load re- } \\
\text { ceiver. Terminate this phase if within achievable limits. } \\
\text { Go to phase 2a (extension, continued straight driving until steering } \\
\text { possible). }\end{array}$ \\
\hline
\end{tabular}




\subsection{Validation}

With the operator model implemented, it can now be validated by running simulations with varying parameter setups and comparing to results from test series.

In our work, both operator models have been tested by varying the machine's technical parameters. For instance, changing the machine's torque converter to a weaker characteristics (as we also have done in our measurement series), leads to a slightly different operating style with in general higher engine speeds, since the operator adapts and quickly finds the necessary amount of gas pedal angle to control traction force. Exactly this phenomenon has also been shown to occur in our simulations, without any explicit coding of it (see Fig. 4, results from first operator model).

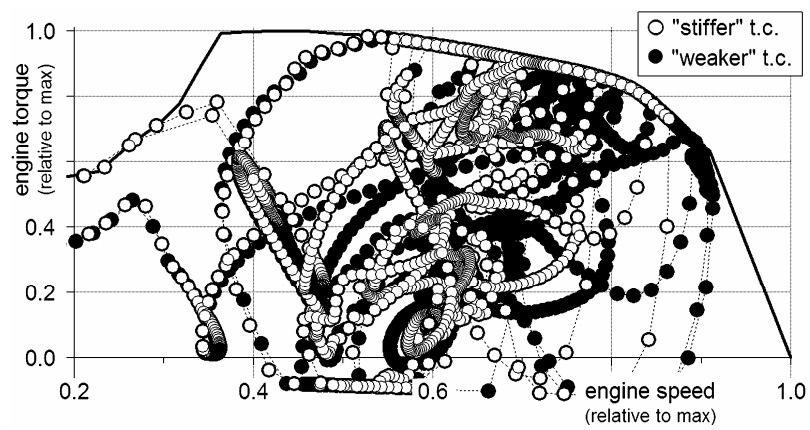

Fig. 4. Engine load duty for machines with different torque converters (first model) [15]

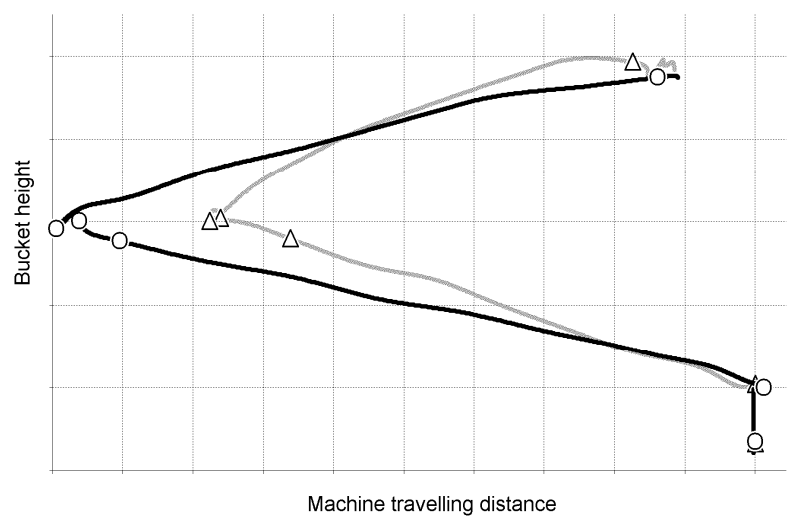

Fig. 5. Adaptation to lifting speed (second model) [16]

Another example is that of changed speed in the bucket's lift hydraulics, emulating insufficient pump capacity. A human operator adapts to this by reversing farther with the wheel loader until finally driving forward to the load receiver to dump the bucket's load. This could also be demonstrated in our simulations without any modification of the operator model. Figure 5 shows traces from experiments with the second operator model (black curve with circular markings: lower lifting speed). 


\section{Conclusion and Outlook}

With both presented operator models, a "human element" has been introduced to dynamic multi-domain simulation of complete construction machinery. Both operator models have been derived from interview studies in a fairly straightforward manner. They prescribe the machine's working cycle in a more generic way, independently of the machine's technical parameters. Due to this, whole components or sub-systems can be changed in their characteristics without compromising the validity of the simulation. This gives more relevant answers with respect to total machine performance, productivity, and fuel consumption.

The results are satisfactory and the methodology is easily usable for other, similar situations.

In the future, we will try to develop operator models with which a machine's operability can be predicted using simulation. As noted earlier, in automotive and aerospace simulations this is usually achieved by analyzing the control effort required to perform predefined maneuvers. A weighed, piece-wise analysis of prominent cycle phases (e.g. bucket filling, reversing and bucket emptying) might be a way forward.

In order to validate any such simulations, we will also work with quantification of work load by simultaneously performing in-depth measurements on a wheel loader in operation and physiological measurements on the operator controlling the machine.

\section{References}

1. Filla, R.: Operator and Machine Models for Dynamic Simulation Construction Machinery. Licentiate thesis, Linköping University, Linköping (2005),

http://urn.kb.se/resolve?urn=urn:nbn:se:liu:diva-4092

2. Vännström, J., Lindholm, S.: Educational Interface for Reducing Fuel Consumption. MSc thesis, Luleå University of Technology, Luleå (2007),

http: / / epubl. luth.se/1402-1617/2007/114/

3. Zhang, R., Carter, D.E., Alleyne, A.G.: Multivariable Control of an Earthmoving Vehicle Powertrain Experimentally Validated in an Emulated Working Cycle. In: Conference paper, ASME 2003 International Mechanical Engineering Congress and Exposition (2003)

4. Stener, P., Snabb, R.: Körbarhetskvantifiering av Hjullastare. MSc thesis, Linköping University, Linköping (2008),

http://urn.kb.se/resolve?urn=urn:nbn: se: liu:diva-11148

5. Boman, M.: On predicting fuel consumption and productivity of wheel loaders. MSc thesis, Luleå University of Technology, Luleå (2006),

http: / / epubl.1tu.se/1402-1617/2006/009/

6. Filla, R.: Anläggningsmaskiner: Hydrauliksystem i multidomäna miljöer. In: Conference paper, Hydraulikdagar (2003)

7. Gellersted, S.: Manövrering av hjullastare (Operation of Wheel Loaders). Technical report, JTI - Institutet för jordbruks- och miljöteknik, Uppsala (2002),

http://www.jti.slu.se/publikat/rapporter/1\&i/r-310sg.pdf

8. Hemami, A.: Motion trajectory study in the scooping operation of an LHD-loader. IEEE Transactions on Industry Applications 30, 1333-1338 (1994),

http://dx.doi.org/10.1109/28.315248 
9. Wu, L.: A Study on Automatic Control of Wheel Loaders in Rock/Soil Loading. Dissertation, University of Arizona, Tucson (2003),

http: / /wwwlib.umi.com/dissertations/fullcit/3090033

10. Macadam, C.C.: Understanding and Modeling the Human Driver. Vehicle System Dynamics 40, 101-134 (2003), http://dx.doi.org/10.1076/vesd.40.1.101.15875

11. Summala, H.: Automatization, automation, and modeling of driver's behavior. Recherche - Transports - Sécurité 66, 35-46 (2000), http: //dx.doi.org/10.1016/S0761-8980

12. Plöchl, M., Edelmann, J.: Driver models in automobile dynamics application. Vehicle System Dynamics 45, 699-741 (2007), http: / / dx.doi.org/10.1080/00423110701432482

13. Bengtsson, J.: Adaptive Cruise Control and Driver Modeling. Licentiate thesis, Lunds Tekniska högskola, Lund (2001)

14. Anderson, M.R., Clark, C., Dungan, G.: Flight test maneuver design using a skill- and rule-based pilot model. In: Conference paper, IEEE International Conference on Intelligent Systems for the 21st Century (1995), http: / /dx.doi.org/10.1109/ICSMC.1995.538188

15. Filla, R., Ericsson, A., Palmberg, J.-O.: Dynamic Simulation of Construction Machinery: Towards an Operator Model. In: Conference paper, IFPE 2005 Technical Conference (2005), http: / /www . arxiv.org/abs / cs . CE/ 0503087

16. Filla, R.: An Event-driven Operator Model for Dynamic Simulation of Construction Machinery. In: Conference paper, $9^{\text {th }}$ Scandinavian International Conference on Fluid Power (2005), http: / / www . arxiv.org/abs/cs.CE/0506033 